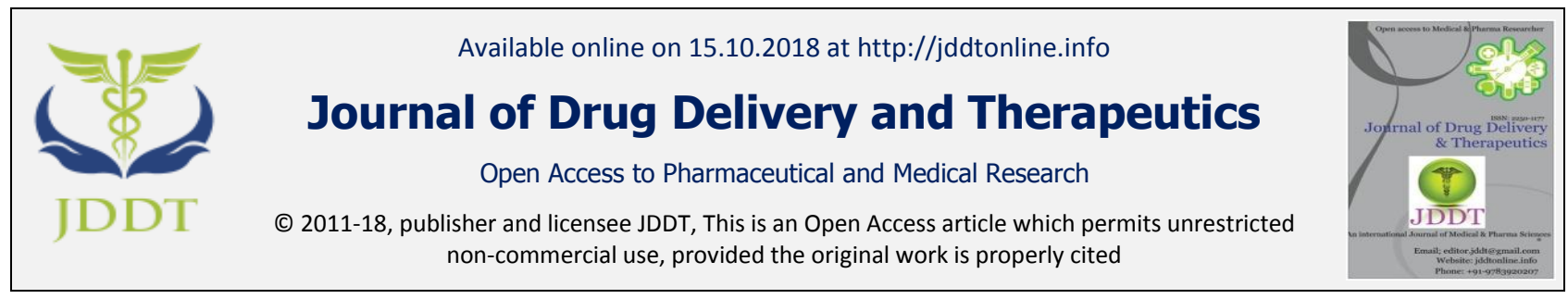

Open $\odot$ Access

Research Article

\title{
PREPARATION AND CHARACTERIZATION OF CHITOSAN NANOPARTICLES OF INSULIN FOR NASAL DELIVERY
}

\author{
Subhendu Sekhar Mishra*, Ashish Sharma \\ Institute of Pharmacy, NIMS University, Jaipur, Rajasthan, india
}

\begin{abstract}
The aim of this study was to prepare and evaluate nanoparticles containing insulin in different polymer ratio by ionotropic gelation method. The average particle size was found to be $33.3 \pm 0.7-69.9 \pm 0.7 \mathrm{~nm}$. SEM indicates that nanoparticles have shown smooth and spherical shape. The zeta potential of optimized formulation was $35.5 \mathrm{mv}$ which indicates moderate stability with no agglomeration. The in vitro drug release data was analyzed using zero order, first order, Higuchi, and Korsmeyer-Peppas models. It was observed the best fit model for nanoparticles was higuchi model. The developed formulation in situ polymeric gel is designed in such a way that the gel will load insulin in higher concentration and it will also contain penetration enhancer which will enhance the absorption of release drug from gel to systemic circulation.
\end{abstract}

Keywords: Insulin, Nanoparticle, invitro drug release study.

Article Info: Received 19 Sep, 2018; Review Completed 12 Oct 2018; Accepted 12 Oct 2018; Available online 15 Oct 2018

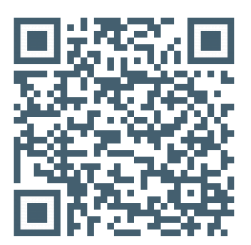

Cite this article as:

Mishra SS, Sharma A, Preparation and characterization of chitosan nanoparticles of insulin for nasal delivery, Journal of Drug Delivery and Therapeutics. 2018; 8(5-s):400-406 DOI: http://dx.doi.org/10.22270/jddt.v8i5-s.2002

\section{*Address for Correspondence:}

Subhendu Sekhar Mishra, Research Scholar, Institute of Pharmacy, Nims University, Jaipur, Rajasthan, India

\section{INTRODUCTION}

Controlled drug delivery system (CDDS) represents the developed technique of pharmaceutical sciences, it's includes various scientific approaches, managing for individual care. The drug development technology having abundant advantages than existing conventional type of dosage, it involves enhanced effectiveness, minimized poisoning, enhanced conformity of the consumer is ease ${ }^{1}$. As a kind of protein and peptide drug, insulin is widely accepted as an effective drug for eliminating the clinical symptoms of diabetes mellitus 2,3 . However, oral insulin has a very low bioavailability due to the destruction of gastric $\mathrm{pH}$ and gastrointestinal enzymes, as well as its low permeability across the intestinal epithelium ${ }^{4,5}$. Currently new and potent Protein/Peptide drugs are generally administered parenterally by IV, IM and SC routes, but needle phobia and stress of multiple daily injections and other associated disadvantages lead to development of new and significant approaches for their delivery. Insulin is given subcutaneously before meal to the patients suffering with insulin dependent diabetes mellitus because insulin is inactivated in gut lumen by its enzymes and acidic environment and of is having very limited GIT permeability as well as injection phobia, discomfortness and cause chances of infection, make necessitate to discover an alternate route which can safely deliver insulin systematically.

Hence, it is envisaged to design such delivery system and select route of administration, which will avoid insulin from its inactivation, absorbed effectively and enhance the bioavailable dose on administration. Nasal insulin delivery is the best way to deliver insulin safely without its degradation. Insulin directly enters into systemic circulation after absorption but low retention time of dosage form make nasal route is very challengeable. To overcome these problems, it is envisaged to formulate a delivery system i.e. in situ biodegradable polymeric gel, which can entrap insulin along with the penetration enhancers that will retain for longer period, protect and make it available to manage blood glucose level in the body. 
In present study a novel drug delivery system i.e. in situ polymeric gel is designed in such a way that the gel will load insulin in higher concentration and it will also contain penetration enhancer which will enhance the absorption of release drug from gel to systemic circulation. Prepared formulation will remain in liquid form before administration but on administer nasal route then it will become gel due to its interaction with lachrymal fluid environment like $\mathrm{pH}$, temperature and ions. Its gel form will retain for longer period of time and work as reservoir for insulin. The in situ gel will release the drug in very sustained and controlled manner as well as it also increases the retention and contact time thus increase the bioavailability of entrapped insulin by making it bioavailable by increase contact time for longer period of time. This novel in situ gel will overcome the disadvantages associated with conventional dosage form (drop and other) like low retention time and immediate absorption of drug that act only for short time. The in situ gel will protect insulin, increase its retention in ocular cavity and release it in very controlled manner for longer period of time which will reduce dose and manage blood glucose level effectively.

\section{MATERIALS AND METHODS}

\section{Materials:}

Insulin was purchase from himedia lab, India. Chitosan was was obtained as a gift sample from Torrent Pharmaceutical Pvt. Ltd (Mumbai, India). Poloxamer 407 was purchase from Sigma Aldrise, India. Carbopol
934 and other chemical purchase from himedia lab, India.

\section{Methods:}

\section{Preparation of chitosan nanoparticles of Insulin}

Nanoparticles (NP) will be prepared according to Calvoet al., 1997 [6], using ionotropic gelation method with slight medication in which chitosan $(0.4 \% \mathrm{w} / \mathrm{v})$ will be dissolved in aqueous acetic acid solutions ( $1 \%$ $\mathrm{v} / \mathrm{v})(\mathrm{pH} 6.1)$, while TPP $(0.1 \% \mathrm{w} / \mathrm{v})$ will be dissolved in deionized water. Insulin solution will be premixed with chitosan solution before the addition of the TPP solution drop wise into the chitosan solution under magnetic stirring $(600 \mathrm{rpm})$ at ambient temperature for $2-4 \mathrm{hr}$. The obtained nanoparticles formulation will be lyophilized and stored in $4-8^{\circ} \mathrm{C}$ until it will further use.

\section{Optimization of process Variable}

The effect of formulation process variables such as stirring time, stirring speed, surfactant concentration on the particle size was studied. From the results obtained, optimum level of those variables was selected and kept constant in the subsequent evaluations.

\section{Effect of chitosan quantity}

The effect of chitosan quantity on the particle size was studied by varying one chitosan Chitosannanoparticles were prepared corresponding to varying concentrations of chitosan such as $0.1,0.2,0.3,0.4,0.5,0.6,0.7,0.8$ and $0.9 \%$ keeping the amount of Acetic acid $(1 \% \mathrm{v} / \mathrm{v})$, stirring time (3 hours) and stirring speed $(600 \mathrm{rpm})$ constant. (Table 1)

Table 1: Composition of SLN by varying amount of lipid

\begin{tabular}{|c|c|c|c|c|c|c|c|c|c|}
\hline \multirow{2}{*}{ Components } & \multicolumn{10}{|c|}{ Formulation code } \\
\cline { 2 - 11 } & F1 & F2 & F3 & F4 & F5 & F6 & F7 & F8 & F9 \\
\hline Insulin & 10 & 10 & 10 & 10 & 10 & 10 & 10 & 10 & 10 \\
\hline Chitosan & $0.1 \%$ & $0.2 \%$ & $0.3 \%$ & $0.4 \%$ & $0.5 \%$ & $0.6 \%$ & $0.7 \%$ & $0.8 \%$ & $0.9 \%$ \\
\hline Acetic acid & $0.1 \%$ & $0.1 \%$ & $0.1 \%$ & $0.1 \%$ & $0.1 \%$ & $0.1 \%$ & $0.1 \%$ & $0.1 \%$ & $0.1 \%$ \\
\hline Stirring speed (rpm) & 600 & 600 & 600 & 600 & 600 & 600 & 600 & 600 & 600 \\
\hline Stirring time (hrs) & 3 & 3 & 3 & 3 & 3 & 3 & 3 & 3 & 3 \\
\hline
\end{tabular}

\subsubsection{Effect of stirring time}

Different batches of chitosan nanoparticles were prepared increasing of stirring time keeping the chitosan concentration $(0.9 \%)$ and stirring speed $(600 \mathrm{rpm})$ constant. (Table 2$)$

Table 2: Composition of chitosan nanoparticle by varying Stirring time

\begin{tabular}{|l|c|c|c|c|c|c|c|c|c|}
\hline \multirow{2}{*}{ Components } & \multicolumn{9}{|c|}{ Formulation code } \\
\cline { 2 - 11 } & F10 & F11 & F12 & F13 & F14 & F15 & F16 & F17 & F18 \\
\hline Insulin & 10 & 10 & 10 & 10 & 10 & 10 & 10 & 10 & 10 \\
\hline Chitosan & $0.9 \%$ & $0.9 \%$ & $0.9 \%$ & $0.9 \%$ & $0.9 \%$ & $0.9 \%$ & $0.9 \%$ & $0.9 \%$ & $0.9 \%$ \\
\hline Acetic acid & $0.1 \%$ & $0.1 \%$ & $0.1 \%$ & $0.1 \%$ & $0.1 \%$ & $0.1 \%$ & $0.1 \%$ & $0.1 \%$ & $0.1 \%$ \\
\hline Stirring speed (rpm) & 600 & 600 & 600 & 600 & 600 & 600 & 600 & 600 & 600 \\
\hline Stirring time (hrs) & 1 & 2 & 3 & 4 & 5 & 6 & 7 & 8 & 9 \\
\hline
\end{tabular}

\section{Effect of stirring speed}

Four different batches of chitosan nanoparticles were prepared corresponding to 100, 200, 300, 400, 500, 600, 700, 800 and $900 \mathrm{rpm}$ of stirring speed keeping the chitosan concentration ( $0.9 \%)$ and stirring time (4 Hour) constant. (Table 3) 
Table 3: Composition of chitosan nanoparticle by varying Stirring speed

\begin{tabular}{|l|l|l|l|l|l|l|l|l|l|}
\hline \multirow{2}{*}{ Components } & \multicolumn{9}{|c|}{ Formulation code } \\
\cline { 2 - 11 } & F10 & F11 & F12 & F13 & F14 & F15 & F16 & F17 & F18 \\
\hline Insulin & 10 & 10 & 10 & 10 & 10 & 10 & 10 & 10 & 10 \\
\hline Chitosan & $0.9 \%$ & $0.9 \%$ & $0.9 \%$ & $0.9 \%$ & $0.9 \%$ & $0.9 \%$ & $0.9 \%$ & $0.9 \%$ & $0.9 \%$ \\
\hline Acetic acid & $0.1 \%$ & $0.1 \%$ & $0.1 \%$ & $0.1 \%$ & $0.1 \%$ & $0.1 \%$ & $0.1 \%$ & $0.1 \%$ & $0.1 \%$ \\
\hline Stirring speed (rpm) & 100 & 200 & 300 & 400 & 500 & 600 & 700 & 800 & 900 \\
\hline Stirring time (hrs) & 4 & 4 & 4 & 4 & 4 & 4 & 4 & 4 & 4 \\
\hline
\end{tabular}

\section{Evaluation of nanoparticles}

\section{Particle size analysis ${ }^{6,7}$}

Particle size analysis The size distributions along the volume mean diameter of the nanoparticles. Particle size of all formulated nanoparticles was in the range between $130.4 \pm 3.4$ to $155.5 \pm 6.4$ and Zeta potential of all formulated nanoparticle was the range between were measured by laser scattering light using photon correlation spectroscopy using a Horiba Zetasizer Instruments. The obtained results are shown in Figure 3.

\section{Entrapment efficiency}

The entrapment efficiency of the drug was defined as the ratio of the mass of formulations associated drug to the total mass of drug. Entrapment efficiency was determined by dialysis method. chitosan nanoparticles entrapped insulin were separated from the free drug by dialysis method. The above said formulations were filled into dialysis bags and the free insulin dialyzed for 24 hours into $50 \mathrm{ml}$ of buffer $\mathrm{pH} \mathrm{1.2.} \mathrm{The} \mathrm{absorbance} \mathrm{of}$ the dialysate was measured at $272.0 \mathrm{~nm}$ against blank buffer pH 1.2 and the absorbance of the corresponding blank was measured under the same condition. The concentration of free insulin could be obtained from the absorbance difference based on standard curve. Standard curve was made by measuring the absorbance at 272.0.0 $\mathrm{nm}$ for known concentrations of insulin solution ${ }^{7}$.

\section{Drug content:}

From the prepared chitosan nano formulation $1 \mathrm{ml}$ of suspension is dissolved in the $10 \mathrm{ml}$ of $1.2 \mathrm{pH}$ buffer. The amount of insulin was determined using UV spectrophotometer at $272 \mathrm{~nm}$. The placebo formulation prepared similarly to drug loaded nanoparticle was used as blank. The total drug content was calculated ${ }^{8}$.

\section{Shape and Surface Characterization of nanoparticle by Scanning Electron Microscopy (SEM):}

From the formulated batches of chitosan nanoparticle optimized formulations which showed an appropriate balance between the percentage release were examined for surface morphology and shape using scanning electron microscope Jeol Japan 6000. Sample was fixed on carbon tape and fine gold sputtering was applied in a high vacuum evaporator. The acceleration voltage was set at $10 \mathrm{KV}$ during scanning. Microphotographs were taken on different magnification and higher magnification (200X) was used for surface morphology.

In-vitro diffusion study: An in-vitro drug release study was performed using modified Franz diffusion cell. Dialysis membrane (Hi Media, Molecular weight 5000
Daltons) was placed between receptor and donor compartments. In-situ gel equivalent to $100 \mathrm{mg}$ of Insulin was placed in the donor compartment and the receptor compartment was filled with phosphate buffer, $\mathrm{pH}$ 6.5. The diffusion cells were maintained at $37 \pm 0.5^{\circ} \mathrm{C}$ with stirring at $50 \mathrm{rpm}$ throughout the experiment. At different time interval, $5 \mathrm{ml}$ of aliquots were withdrawn from receiver compartment through side tube and analyzed for drug content by UV Visible spectrophotometer.

Mathematical treatment of in-vitro release data: The quantitative analysis of the values obtained in dissolution/release tests is easier when mathematical formulas that express the dissolution results as a function of some of the dosage forms characteristics are used.

1. Zero-order kinetics ${ }^{9}$ : The pharmaceutical dosage forms following this profile release the same amount of drug by unit of time and it is the ideal method of drug release in order to achieve a pharmacological prolonged action. The following relation can, in a simple way, express this model:

$$
\mathbf{Q}_{\mathrm{t}}=\mathbf{Q}_{\mathrm{o}}+\mathbf{K}_{\mathrm{o}} \mathrm{t}
$$

where $Q_{t}$ is the amount of drug dissolved in time $t, Q_{0}$ is the initialamount of drug in the solution (most times, $\mathrm{Q}_{\mathrm{o}}=0$ ) and $\mathrm{K}_{\mathrm{o}}$ is the zero order release constant (Bourne, 2002).

2. First-order kinetics ${ }^{10}$ : The following relation expresses this model:

$$
\log Q_{t}=\log Q_{0}+\frac{K_{1} t}{2.303}
$$

where $\mathrm{Q}_{\mathrm{t}}$ is the amount of drug dissolved in time $\mathrm{t}, \mathrm{Q}_{\mathrm{o}}$ is the initialamount of drug in the solution and $K_{1}$ is the zero order release constant.

In this way a graphic of the decimal logarithm of the released amount of drug versus time will be linear. The pharmaceutical dosage forms following this dissolution profile, such as those containing water-soluble drugs in porous matrices, release drug in a way that is proportional to the amount of drug remaining in its interior, in such way, that the amount of drug released by unit of time diminish.

3. Higuchi model ${ }^{11}$ : Higuchi developed several theoretical models to study the release of water-soluble and low soluble drugs in semi-solid and/or solid matrixes. Mathematical expressions were obtained for drug particles dispersed in a uniform matrix behaving as 
the diffusion media. The simplified Higuchi model is expressed as:

$$
\mathrm{Q}=\mathrm{K}_{\mathbf{H}^{\cdot}} \mathbf{t}^{\mathbf{1} / 2}
$$

where $\mathrm{Q}$ is the amount of drug released in time $\mathrm{t}$ and $\mathrm{K}_{\mathrm{H}}$ is the Higuchi dissolution constant. Higuchi model describes drug release as a diffusion process based in the Fick's law, square root time dependent. This relation can be used to describe the drug dissolution from several types of modified release pharmaceutical dosage forms such as transdermal systems and matrix tablets with water-soluble drugs.

4. Korsmeyer-Peppasmodel: Korsmeyeret al. used a simple empirical equation to describe general solute release behaviour from controlled release polymer matrices:

$$
\frac{M_{t}}{M_{m}}=a t^{n}
$$

where $M_{t} / M_{\infty}$ is fraction of drug released, $a$ is kinetic constant, $\mathrm{t}$ is release time and $\mathrm{n}$ is the diffusional exponent for drug release. ' $\mathrm{n}$ ' is the slope value of log $M_{t} / M_{\infty}$ versus log time curve ${ }^{12}$. Peppas stated that the above equation could adequately describe the release of solutes from slabs, spheres, cylinders and discs, regardless of the release mechanism [13]. Peppas used this $n$ value in order to characterize different release mechanisms, concluding for values for a slab, of $n=0.5$ for fickian diffusion and higher values of $n$, between 0.5 and 1.0, or $n=1.0$, for mass transfer following a nonfickian model (Table 3 ). In case of a cylinder $n=0.45$ I nstead of 0.5 , and 0.89 instead of 1.0. This equation can only be used in systems with a drug diffusion coefficient fairly concentration independent [13]. To the determination of the exponent $n$ the portion of the release curve where $M_{t} / M_{\infty}<0.6$ should only be used. To use this equation it is also necessary that release occurs in a one-dimensional way and that the system widththickness or length-thickness relation be at least 10. A modified form of this equation was developed to accommodate the lag time $(l)$ in the beginning of the drug release from the pharmaceutical dosage form:

$$
\frac{\mathrm{M}_{\mathrm{t} \cdot l}}{\mathrm{M}_{\mathbf{m}}}=\mathrm{a}(\mathrm{t}-l)^{n}
$$

When there is the possibility of a burst effect, b, this equation becomes:

$$
\frac{M_{t}}{M_{m}}=a t^{n}+b
$$

In the absence of lag time or burst effect, 1 and bvalue would be zero and only at ${ }^{n}$ is used. This mathematical model, also known as Power Law, has been used very frequently to describe release from several different pharmaceutical modified release dosage forms.

Table 3: Interpretation of diffusional release mechanisms.

\begin{tabular}{|l|l|l|}
\hline Release exponent $(\boldsymbol{n})$ & Drug transport mechanism & Rate as a function of time \\
\hline 0.5 & Fickian diffusion & $\mathrm{t}^{-0.5}$ \\
\hline $0.5<n<1.0$ & Anomalous transport & $\mathrm{t}^{\mathrm{n}-1}$ \\
\hline 1.0 & Case-II transport & Zero-order release \\
\hline Higher than 1.0 & Super Case-II transport & $\mathrm{t}^{\mathrm{n}-1}$ \\
\hline
\end{tabular}

\section{RESULTS AND DISCUSSION}

\section{Particle size analysis}

The size distributions along the volume mean diameter of the nanoparticles. Particle size of all formulated nanoparticles was in the range between $130.4 \pm 3.4$ to 155.5 \pm 6.4 . The zeta potential of optimized formulation was $35.5 \mathrm{mv}$ which indicates moderate stability with no agglomeration. The obtained results are shown in table 4. Results showed that in formulation F-17 which contains higher level of chitosan and high stirring speed showed decrease in particle size and increase in entrapment efficiency, as level of chitosan decreased particle size of formulation increased. 
Table 4: Evaluations of Nanoparticle formulations by OVAT

\begin{tabular}{|l|c|c|c|}
\hline Formulation & Particle Size $(\mathbf{n m})$ & Entrapment efficiency $\mathbf{( \% )}$ & Drug content $\mathbf{\%})$ \\
\hline F1 & $55.2 \pm 0.4$ & $71.2 \pm 0.5$ & $69.98 \pm 0.45$ \\
\hline F2 & $45.6 \pm 0.6$ & $62.2 \pm 0.6$ & $73.28 \pm 0.65$ \\
\hline F3 & $60.1 \pm 0.8$ & $65.4 \pm 0.4$ & $70.56 \pm 0.85$ \\
\hline F4 & $48.7 \pm 0.7$ & $63.1 \pm 0.5$ & $65.52 \pm 0.45$ \\
\hline F5 & $55.6 \pm 1.2$ & $61.2 \pm 0.8$ & $66.92 \pm 0.65$ \\
\hline F6 & $69.9 \pm 0.7$ & $60.2 \pm 0.9$ & $68.98 \pm 0.32$ \\
\hline F7 & $65.5 \pm 0.5$ & $59.9 \pm 0.1$ & $71.12 \pm 0.25$ \\
\hline F8 & $55.6 \pm 0.4$ & $60.2 \pm 0.5$ & $69.98 \pm 0.26$ \\
\hline F9 & $65.4 \pm 0.6$ & $58.8 \pm 0.3$ & $73.12 \pm 0.21$ \\
\hline F10 & $52.2 \pm 0.8$ & $63.3 \pm 0.5$ & $70.56 \pm 0.45$ \\
\hline F11 & $41.2 \pm 0.9$ & $60.2 \pm 0.4$ & $69.98 \pm 0.36$ \\
\hline F12 & $52.2 \pm 0.7$ & $65.5 \pm 0.5$ & $73.12 \pm 0.25$ \\
\hline F13 & $45.5 \pm 0.8$ & $68.9 \pm 0.6$ & $75.45 \pm 0.45$ \\
\hline F14 & $55.6 \pm 0.6$ & $73.3 \pm 0.7$ & $73.45 \pm 0.78$ \\
\hline F15 & $60.2 \pm 0.6$ & $75.4 \pm 0.6$ & $78.98 \pm 0.65$ \\
\hline F16 & $45.5 \pm 0.9$ & $79.9 \pm 0.2$ & $85.62 \pm 0.67$ \\
\hline F17 & $33.3 \pm 0.7$ & $82.5 \pm 0.3$ & $89.98 \pm 0.45$ \\
\hline F18 & $65.5 \pm 0.5$ & $78.8 \pm 0.2$ & $75.55 \pm 0.55$ \\
\hline
\end{tabular}

Particle size and zeta potential drug content of optimized formulation

\begin{tabular}{|c|c|c|c|}
\hline Code & $\begin{array}{c}\text { Entrapment efficiency } \\
(\boldsymbol{\%})\end{array}$ & $\begin{array}{c}\text { Zeta potential } \\
(\mathbf{m v})\end{array}$ & $\begin{array}{c}\text { Particle size } \\
(\mathbf{n m})\end{array}$ \\
\hline F17 & $78.8 \pm 0.2$ & -35.5 & $33.3 \pm 0.7$ \\
\hline
\end{tabular}

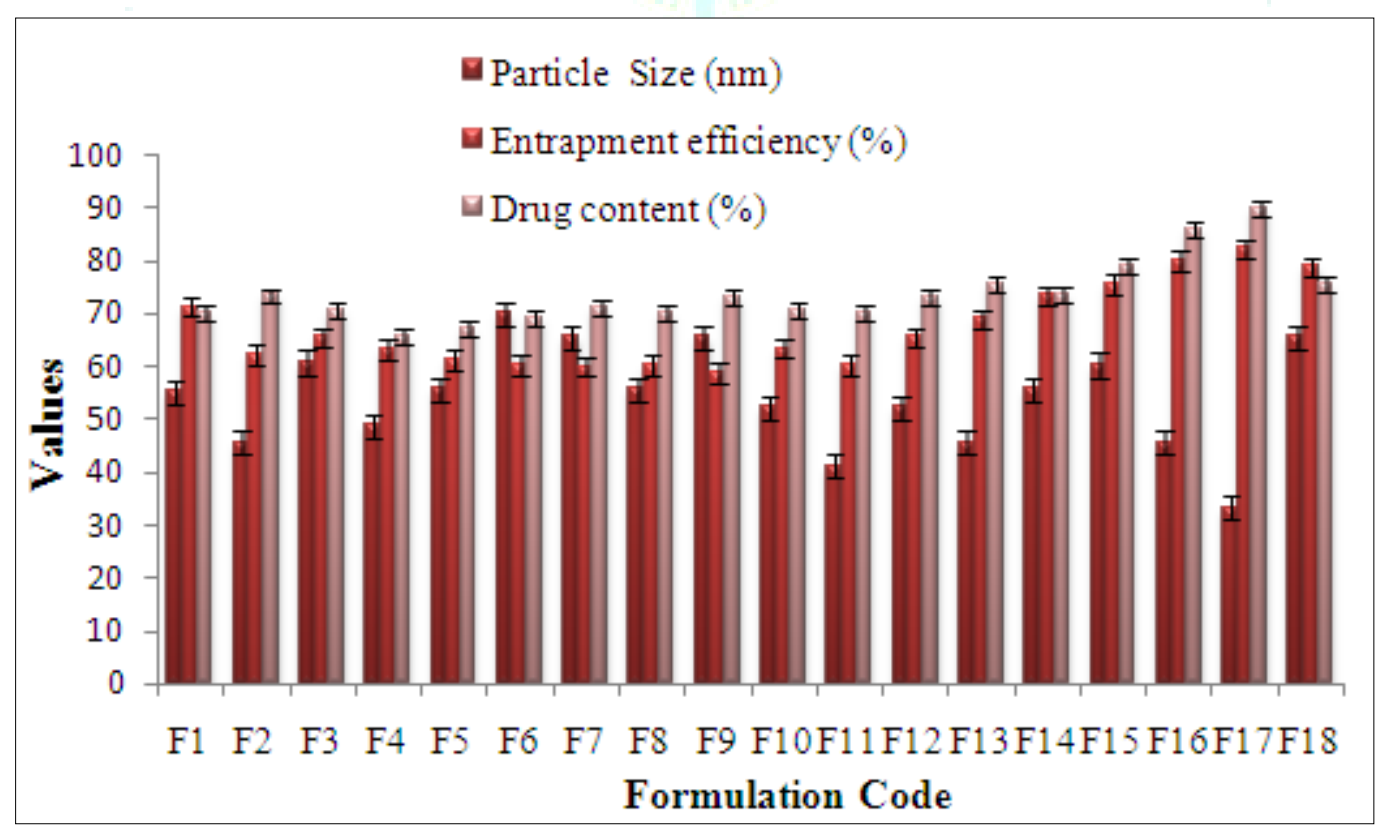

Figure 1: Evaluation of Nanoparticle formulations by OVAT 


\section{Shape and Surface morphology}

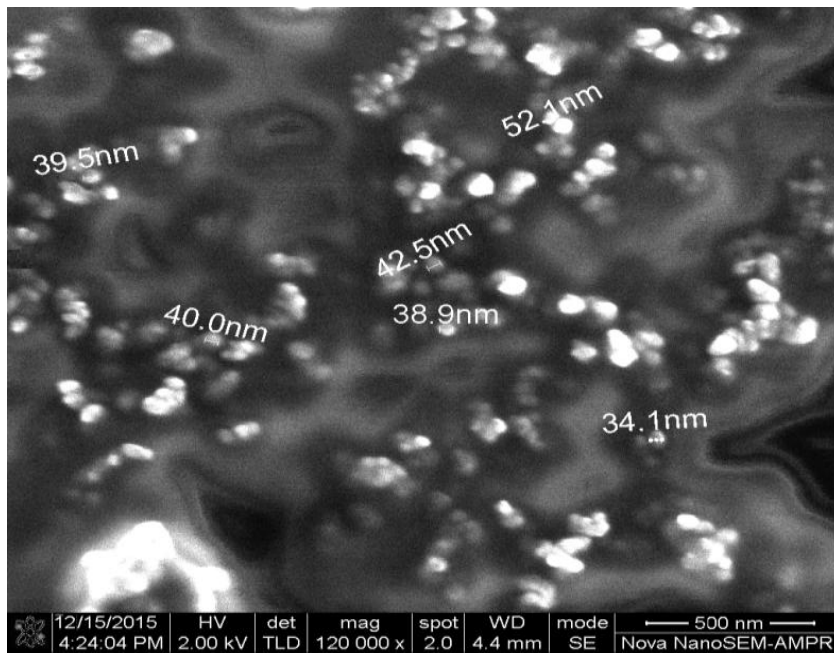

Figure 2: Scanning Electronic Microscopy Image of Optimized Formulation

Shape and surface morphology of nanoparticles was studied by Scanning Electron Microscopy (SEM). SEM photographs of optimized formulations were shown in Figure 2. Insulin nanoparticles have shown smooth and spherical shape with different sizes depending on the ratios of the surfactant and polymer used.

\section{In Vitro drug release Study}

The in vitro release profile of optimized formulation is shown in fig.2. The optimized Insulin NPs showed initial burst release of $22.25 \pm 1.3 \%$, optimized Insulin NPs showed sustained drug release with maximum drug release of $93.32 \pm 0.8 \%$ in 12 hours. Thus, it was clear that incorporation of Insulin nanoparticles could significantly sustain the release. The in vitro drug release data was analyzed using zero order, first order, Higuchi, and Korsmeyer-Peppas models. The graph for Higuchi model was plotted between log time and log percentage drug remaining and the correlation coefficient was found $(r 2) 0.981$ for in vitro drug release, therefore the best fit model for nanoparticles was higuchi model.

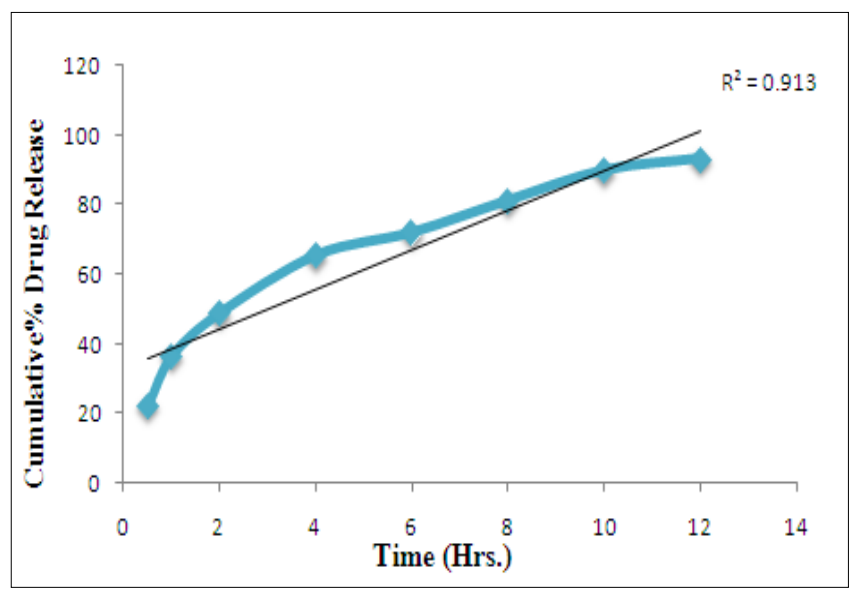

Zero order release Kinetics of optimized Formulation

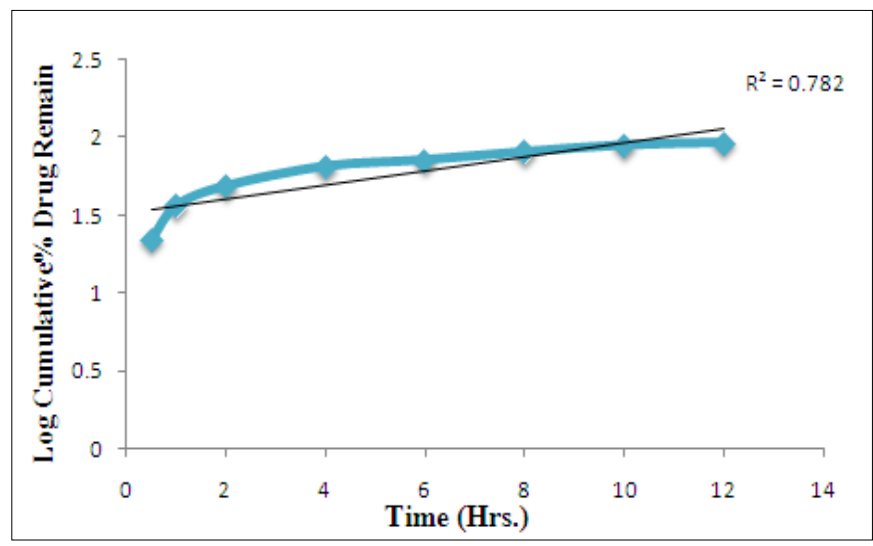

First order release Kinetics of optimized Formulation

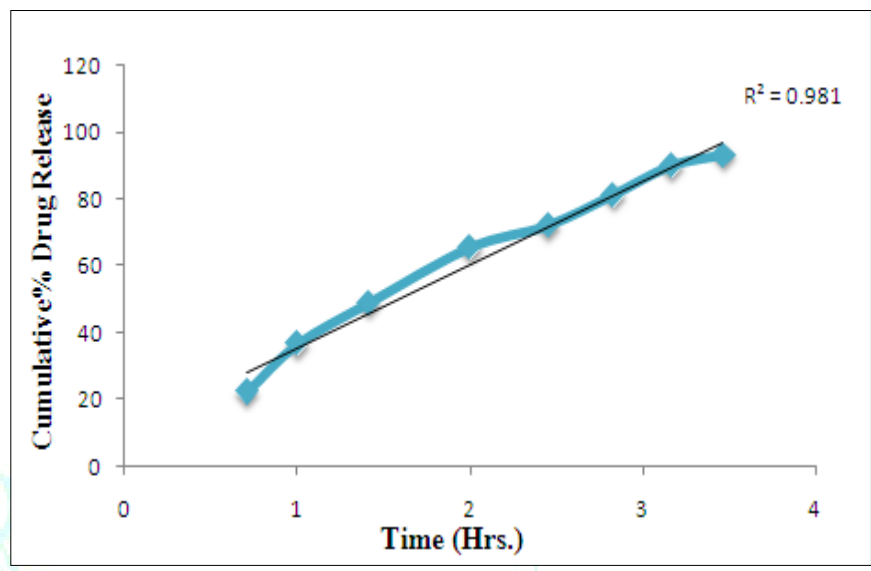

Higuchi release Kinetics of optimized Formulation

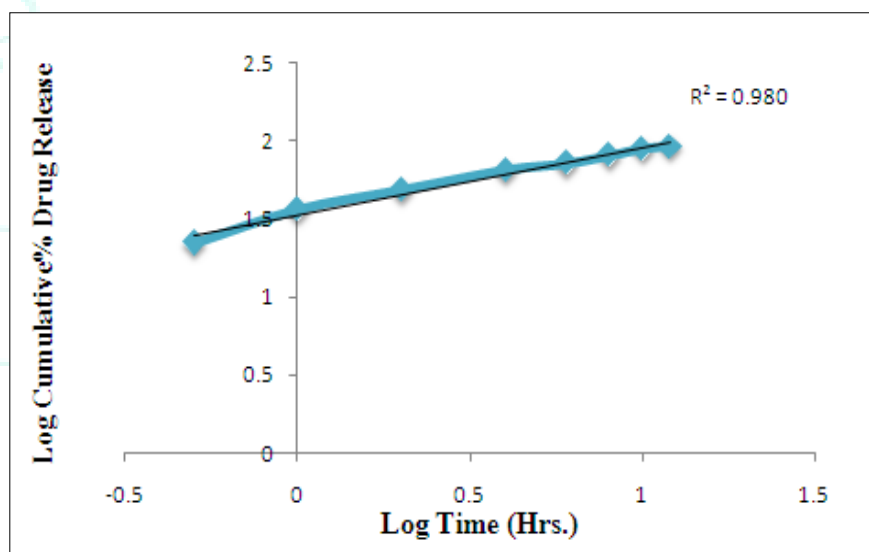

Graph of Peppas release Kinetics

Regression analysis data of optimized formulation

\begin{tabular}{|c|c|c|c|c|}
\hline \multirow{2}{*}{ Batch } & $\begin{array}{c}\text { Zero } \\
\text { Order }\end{array}$ & $\begin{array}{c}\text { First } \\
\text { Order }\end{array}$ & Higuchi & $\begin{array}{c}\text { Korsmeyer- } \\
\text { Peppas }\end{array}$ \\
\cline { 2 - 5 } & $\mathbf{R}^{\mathbf{2}}$ & $\mathbf{R}^{\mathbf{2}}$ & $\mathbf{R}^{\mathbf{2}}$ & $\mathbf{R}^{\mathbf{2}}$ \\
\hline F9 & 0.913 & 0.782 & 0.981 & 0.980 \\
\hline
\end{tabular}

When the regression coefficient values of were compared, it was observed that ' $r$ ' values of KorsmeyerPeppas was maximum i.e. 0.980 hence indicating drug release from formulations was found to follow Korsmeyer-Peppas release kinetics. 


\section{CONCLUSION}

Insulin loaded polymeric nanoparticle showed slow and constant release of insulin from nanoparticles maintain constant drug plasma concentration thereby increasing therapeutic efficacy. In situ polymeric gel is designed in such a way that the gel will load insulin in higher concentration and it will also contain penetration

\section{REFERENCES}

1. Kuzuya, T.; Nakagawa, S.; Satoh, J.; Kanazawa, Y.; Iwamoto, Y.; Kobayashi, M.; Nanjo, K.Sasaki, A.; Seino, Y.; Ito, C.; Shima, K.; Nonaka, K.; Kadowaki, T. Diabetes Res. Clin. Pract 2002; 55(1):65-69.

2. Attivi, D. Wehrle, P. Ubrich, N. Damge, C. Hoffman, M. Maincent, P. Drug. Dev. Ind. Pharm. 2005; 31(2):179.

3. Sarmento, B. Ribeiro, A. Veiga, F. Sampaio, P. Neufeld, R. Ferreira, D. Pharm. Res. 2007; 24(12):2198.

4. Bachnav D., Rao M., Madgulkar A., Rao S., Nanotechnology and blood brain barrier, Indian Drug, 2007; 44:245-252.

5. Chen D.B., Yang T. Z., Lu W. L., Zhang Q., In vitro and in vivo study of two types of long circulating solid lipid nanoparticles containing pacitaxel, Chem. Pharm. Bull., 2001; 49:1444- 1447.

6. Calvo et al, Novel Hydrophilic Chitosan-Polyethylene Oxide Nanoparticles as Protein Carriers, Journal of Applied Polymer Science 1997; 63:125-132.

7. Peltonen L, Koistinen $\mathrm{P}$, Karjalainen M, Hakkinen A, Hirvonen J. The effect of cosolvents on the formulation of nanoparticles from low molecular weight poly(l)lactide, AAPS PharmSciTech, 2002; 3:1-7. enhancer which will enhance the absorption of release drug from gel to systemic circulation. Prepared formulation will remain in liquid form before administration but on administer nasal route then it will become gel due to its interaction with lachrymal fluid environment like $\mathrm{pH}$, temperature and ions. Its gel form will retain for longer period of time and work as reservoir for insulin.

8. Cui F, Oian F, Yin C. Preparation and characterization of mucoadhesive polymercoated nanopaticles, Int. J. Pharm., 2006, 316, 154-161.

9. Mahjub R, Dorkoosh FA, Amini M, Khoshayand MR, Rafiee-tehrani M. Preparation, statistical optimization, and in vitro characterization of insulin nanoparticles composed of quaternized aromatic derivatives of chitosan, AAPS Pharm Sci Tech, 2011; 12:1407-1419.

10. Haznedar S., Dortunc B., Preparation and evaluation of Eudragit microspheres containing acetazolamide, Int. J. Pharm.,2004; 269:131- 140.

11. Higuchi T., Mechanism of sustained action medication: theoretical analysis of rate of release of solid drugs dispersed in solid matrices, J. Pharm. Sci., 1963; 52:1145-1149.

12. Korsmeyer RW, Gurny R, Doelker E, Buri P, Peppas NA. Mechanisms of solute release from porous hydrophilic polymers Int. J. Pharm., 1983; 15:25-35.

13. Peppas N. Analysis of Fickian and non-Fickian drug release from polymers Pharm. Acta Helv., 1985; 60:110-111. 